\title{
Multi-Level Optimization Approach for Directly Coupled Photovoltaic-Electrolyser System
}

A. Khalilnejad ${ }^{1}$, A. Abaspour ${ }^{2}$, A. I. Sarwat ${ }^{1}$

${ }^{1}$ Electrical Engineering Department, Center of Energy, Power \& Sustainability (EPS), Florida International 5

$\begin{array}{lr}\text { University (FIU), Miami, USA } & 6\end{array}$

${ }^{2}$ Electrical Engineering Department, Florida International University (FIU), Miami, USA 7

$\begin{array}{lr}\text { Abstract: } & 9\end{array}$

In this study, directly coupled photovoltaic-electrolyser system is designed and optimized and a new

method for optimization is given. The accurate electrical models of advanced alkaline electrolyser,

photovoltaic system, and hydrogen storage tank are simulated using Matlab. The system is investigated

performed using genetic algorithm, is to produce maximum hydrogen, minimum excess power, and minimum energy transfer loss. In each iteration of the optimization, due to crucial role of temperature in overall performance of the system, the average operating temperature is optimized using genetic loss.

Keywords: Photovoltaic, Advanced alkaline electrolyser, GA optimization, Hydrogen production, Directly coupled 
Introduction:

The rising demand for new procedures of energy production and storage has been the focus of study in

For the combined PV electrolyser system, several studies have been done [6, 7, 8, 9]. In a study in algorithm and the buck-boost converter, which connects the PV array to electrolyser, is controlled. In 
for direct-coupled PV-PEM electrolyser was proposed for relative sizing between components based on

transfer loss. In 2014, a novel integrated system was proposed that by using energy and exergy

methodology, combined photocatalysis, photovoltaics, thermal engine and chemical energy storage for

better solar energy harvesting [22]. In 2014, multi-objective optimization of direct coupling of PV-

based on minimum energy transfer loss, which is equal to the difference of power of maximum power

point to the power of system. In another study, hydrogen generation is maximized by optimizing the size

and the operating conditions of an electrolyser directly connected to a photovoltaic module at different

irradiances using particle swarm optimization (PSO) [24]. In mentioned studies, the objective is to

minimize the gap between actual operational points and maximum power points. In another study,

Optimization and sensitivity analysis of directly coupled photovoltaic-electrolyser system in Beijing is

performed. Parameter of $\mathrm{V} / \mathrm{V}_{\mathrm{m}}$ as the ratio of actual voltage to voltage of maximum power point was

In this study, the electrical performance of combined PV-Electrolyser system is evaluated and the 
hour period is given. Finally, for validation of the results, a comparison with another study is given. The

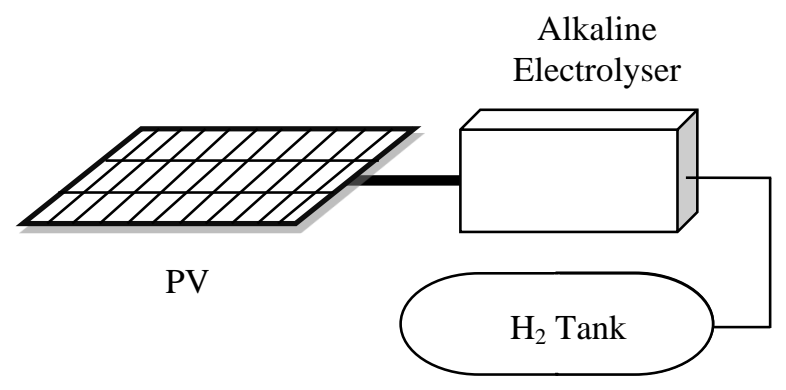

Figure 1. Simplified schematic of directly coupled PV-Electrolyser system with hydrogen storage

\section{Electrolyser}

Alkaline electorlysers are one of the most widely used instruments for hydrogen production through water

electrolysis. For conduction of ions between the electrodes liquid electrolyte is used. Because of the optimal conductivity and corrosion resistance of the stainless steel, potassium hydroxide $(\mathrm{KOH})$ is widely used as electrolyte. The reactions for the alkaline electrolyser anode and cathode is given by

Cathode $: 2 \mathrm{H}_{2} \mathrm{O}_{(l)}+2 e^{-} \longrightarrow \mathrm{H}_{2(g)}+2 \mathrm{OH}_{(\text {(aq })}^{-}$

Anode $: 2 \mathrm{OH}_{(a q)}^{-} \longrightarrow \frac{1}{2} \mathrm{O}_{2(g)}+\mathrm{H}_{2} \mathrm{O}_{(l)}+2 e^{-}$

Electricity is needed for the process of hydrogen production. The electrical equivalent of electrolyser can 95 be considered as a nonlinear load that as the input voltage rises, more hydrogen is produced, due to 96 current increase. In addition, the power rises, which is restricted to the power characteristics of power 97 delivery source. The U-I characteristics of an advanced alkaline electrolyser is defined as [27]

$U_{\text {electrolyser,Cell }}=U_{\text {reversible }}+\frac{r_{1}+r_{2} T}{A} I+s \log \left(\frac{t_{1}+t_{2} / T+t_{3} / T^{2}}{A} I+1\right)$

where $U_{\text {electrolyser,cell }}$ is the cell terminal voltage $(\mathrm{V}), U_{\text {reversible }}$ is reversible cell voltage $(\mathrm{V}), r_{1}, r_{2}$ are 
parameters for overvoltage $\left(\mathrm{V}, \mathrm{m}^{2} / \mathrm{A}, \mathrm{m}^{2} \cdot{ }^{\circ} \mathrm{C} / \mathrm{A}, \mathrm{n} \mathrm{m}^{2} \cdot{ }^{\circ} \mathrm{C}^{2} / \mathrm{A}\right), A$ is the area of cell electrode $\left(\mathrm{m}^{2}\right), I$ is

electrolyser current (A), and $T$ is cell temperature $\left({ }^{\circ} \mathrm{C}\right) . U_{\text {reversible }}$ is given by the Gibbs free energy change

$U_{\text {reversible }}=-\frac{\Delta G}{z F}$

where, $z$ is the number of molecules transferred per hydrogen molecule which is $2, \Delta G$ is Gibbs free energy, and $F$ is Faraday constant. So, $U_{\text {reversible }}$ can be expressed as an empirical equation as

$U_{\text {reversible }}=U_{\text {reversible }}^{0}-k_{\text {reversible }}(T-25)$

where $U^{0}{ }_{\text {reversible }}$ is the reversible cell voltage at standard condition (V), and $k_{\text {reversible }}$ is empirical

temperature coefficient of $U_{\text {reversible }}\left(\mathrm{V} /{ }^{\circ} \mathrm{C}\right)$. For the electrolyser cells connected in series the current is the same and the voltage is

$U_{\text {electrolyser }}=n_{c} \cdot U_{\text {electrolyser, cell }}$

Knowing the voltage and current of the electrolyser, the amount of hydrogen production can be derived as

$\dot{n}_{H_{2}}=\eta_{F} \frac{n_{c} I}{2 F}$

where $\dot{n}_{\mathrm{H}_{2}}$ is the hydrogen production rate (mol/s) and $\eta_{F}$ is the current (Faraday) efficiency. With

increasing of the current, the ratio of parasitic current at the electrolyte decreases and causes $\eta_{F}$ to

increase. The equation of Faraday efficiency can be given as

$$
\eta_{F}=\frac{(I / A)^{2}}{f_{1}+(I / A)^{2}} f_{2}
$$

where $f_{1}\left(\mathrm{~mA}^{2} \mathrm{~cm}^{-4}\right)$, and $f_{2}$ are parameters in current efficiency calculation. The current efficiency is

also a function of the temperature, as the current of the electrolyser varies with temperature. When the

temperature rises, the resistance of water decreases and the efficiency increases. However, at very high 
efficiency. Although Due to thermal operation of the electrolyser system, and heat balance of the

Table 1. Parameters of electrical characteristics of alkaline electrolyser [28]

\begin{tabular}{lcccccccr}
\hline Parameter & $\boldsymbol{r}_{1}$ & $\boldsymbol{r}_{2}$ & $\boldsymbol{t}_{1}$ & $\boldsymbol{t}_{2}$ & $\boldsymbol{t}_{3}$ & $\boldsymbol{A}$ & $f_{1}$ & $f_{2}$ \\
\hline Value & $7.3 \times 10^{-5} \Omega m^{2}$ & $-1.1 \times 10^{-7} \Omega m^{2} C^{-1}$ & $-1.002 \mathrm{~A}^{-1} \mathrm{~m}^{2}$ & $8.424 \mathrm{~A}^{-1} \mathrm{~m}^{2} \mathrm{C}$ & $247.3 \mathrm{~A}^{-1} \mathrm{~m}^{2} \mathrm{C}^{2}$ & $0.25 \mathrm{~m}^{2}$ & $250 \mathrm{~mA}^{2} \mathrm{~cm}^{-4}$ & 0.96 \\
\hline
\end{tabular}

\section{Hydrogen Storage System}

The equation for storage pressure of the hydrogen using its flow rate is calculated using physical

$$
P_{b}-P_{b i}=z \frac{n_{H_{2}} R T_{b}}{M_{H_{2}} V_{b}}
$$

where $M_{H 2}$ is the molar mass of hydrogen $\left(\mathrm{kg} \mathrm{kmol}^{-1}\right), P_{b i}, P_{b}$ are the initial and operating pressure of

The assessment of the solar cells must be based on the electrical characteristics of the photovoltaic 


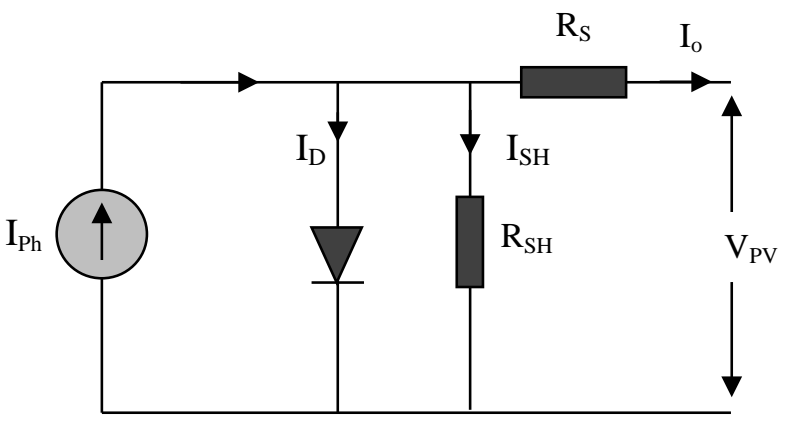

139

Figure 2. Model of photovoltaic cell

Based on the model of photovoltaic cell, shown in figure 2, the current of the cell is expressed as [31]

$I_{o, \text { cell }}=I_{p h}-I_{d}-I_{s h}$

where $I_{p h}$ is the current generated by irradiance (A) which is proportional to solar irradiation, $I_{d}$ is the

current of diode (A), and $I_{s h}$ is the current of parallel resistor (A). For the PV array with combination of

PV cells, the output current is given by

$I_{0}=N_{p} I_{p h}-N_{p} I_{r s}\left[e^{\frac{q\left(V+R_{s} I_{0}\right)}{A . k . T . N_{s}}}-1\right]-N_{p} \frac{q\left(\mathrm{~V}+\mathrm{R}_{\mathrm{s}} \mathrm{I}_{0}\right)}{N_{s} R_{s h}}$

where, $I_{r s}(\mathrm{~A})$ is the cell reveres saturation current, $k$ is Boltzman constant, $T$ is the temperature of the cells (K), $N_{s}$ and $N_{P}$ are the number of PV cells in series and parallel, $q$ is the electron charge, and $A$ is the 147 p-n junction ideality factor. $I_{p h}(\mathrm{~A})$ is proportional to solar irradiance by

$I_{p h}=\frac{G}{1000}\left(\mathrm{I}_{\mathrm{SC}}+\mathrm{k}_{\mathrm{i}}\left(\mathrm{T}-\mathrm{T}_{\mathrm{r}}\right)\right)$

where, $I_{s c}(A)$ is the short circuit current, $k_{i}$ is the short circuit current coefficient, $T_{r}$ is the cell reference 149 temperature, and $g$ is the solar radiation. Also, the saturation current of the cells which is highly 150 dependent to temperature is given by

$I_{r s}=I_{r r}\left[\frac{T}{T_{r}}\right] \exp \left(\frac{q \cdot E_{G}}{k \cdot A}\left(\frac{1}{T_{r}}-\frac{1}{T}\right)\right)$ 
where, $I_{r r}(\mathrm{~A})$ is the reverse saturation current at reference temperature which is dependent to the material

of the PV cell, $E_{G}$ is the energy of the band gap of the cells, and $T_{r}(\mathrm{~K})$ is the reference temperature. The specifications of the used PV modules is given in Table 2.

As it is shown in figure 3, for getting the maximum power from the photovoltaic array, the derivative of

by

$\frac{d P}{d V}=0$

So,

$\frac{d P}{d V}=\frac{d(V I)}{d V}=V \frac{d I}{d V}+I=0$

$\frac{d I}{d V}=-\frac{I}{V}$ at $\mathbf{M P P}$

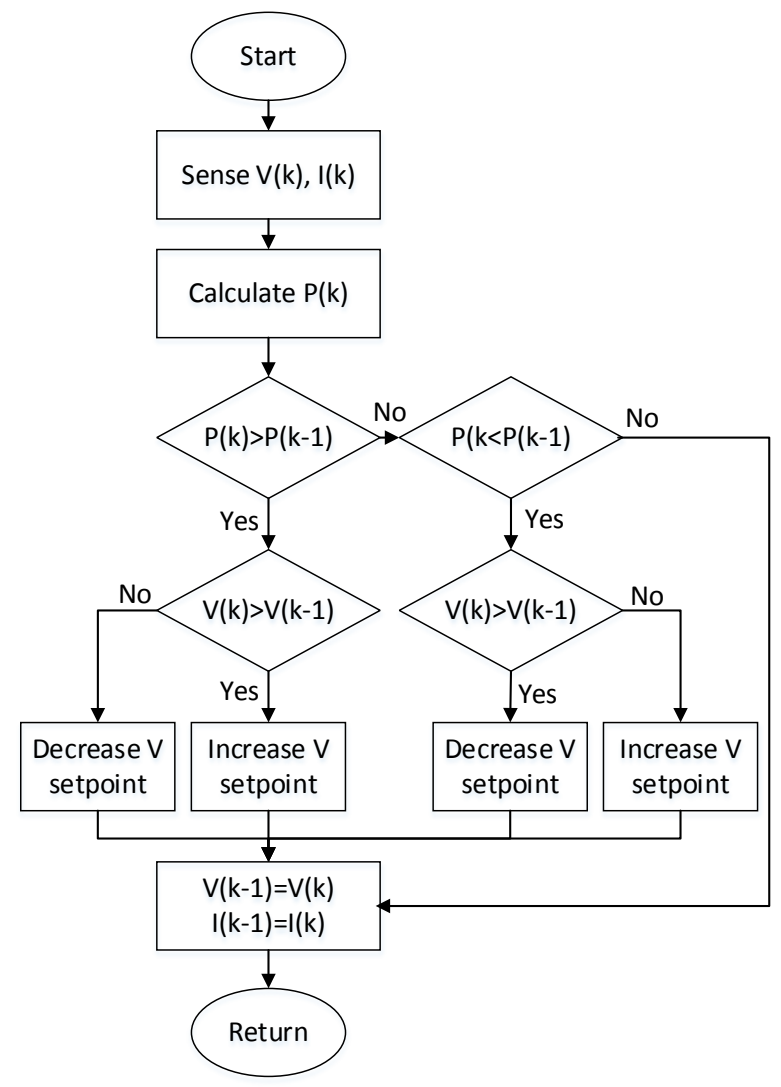

Figure 3. Maximum Power Point Tracking 
Table 2. Specification of the photovoltaic module

\begin{tabular}{llllllllll}
\hline Parameter & $P_{m}$ & $V_{o c}$ & $I_{s c}$ & $V_{M P}$ & $I_{M P}$ & $E_{G}$ & $A$ & $T_{r}$ & $Q$ \\
\hline Value & $45 \mathrm{~W}$ & $21.93 \mathrm{~V}$ & $2.66 \mathrm{~A}$ & $18.85 \mathrm{~V}$ & $2.47 \mathrm{~A}$ & $1.6 \mathrm{eV}$ & $0.75 \mathrm{~m}^{2}$ & $25^{\circ} \mathrm{C}$ & $1.6 \times 10^{-19}$ \\
\hline
\end{tabular}

The combination of the photovoltaic system and electrolyser is possible directly or with DC/DC power

electronics converter. As it is shown in figure 4, the individual characteristics of PV systems and

electrolyser are in a way that, the system can be very close to MPP. Several factors including number of

PV panels in series and parallel, the operating temperature of the electrolyser, and the number of the points.

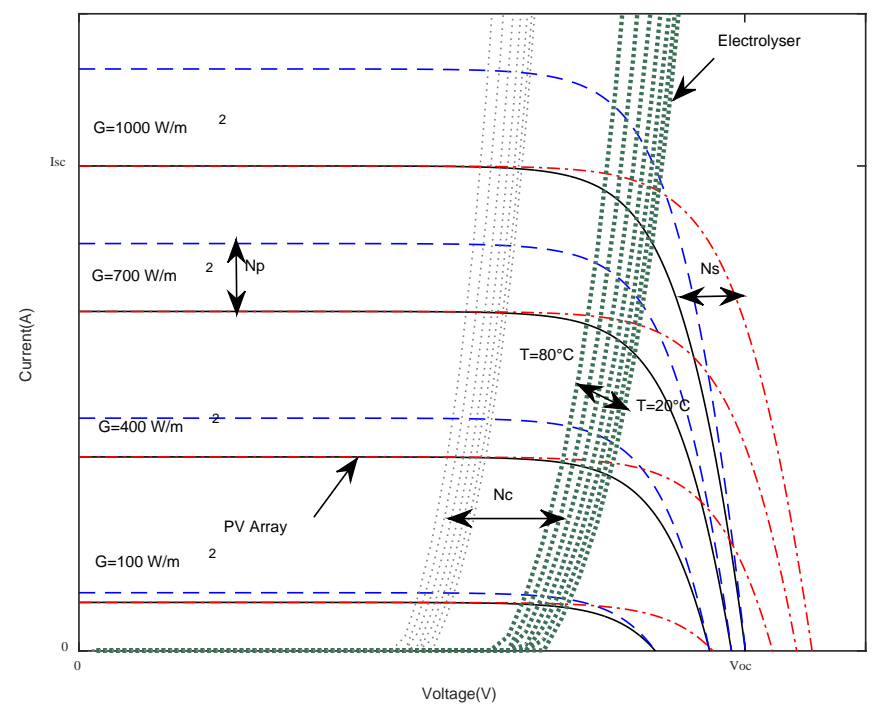

Figure 4. U-I characteristics of photovoltaic system and alkaline electrolyser

With using a DC/DC converter, it is possible to get the maximum power of the photovoltaic system and 
needed power to electrolyser. So, an optimum operating condition for a directly coupled PV-electrolyser

should be proposed. On the other hand, the dimensions of the PV system for getting maximum hydrogen

from the electrolyser are needed to be optimized. Because of the changing of the price of the PV system,

another index for optimization has been proposed. So, the optimization function is based on maximum

hydrogen production of electrolyser with minimum excess power production of PV system and minimum

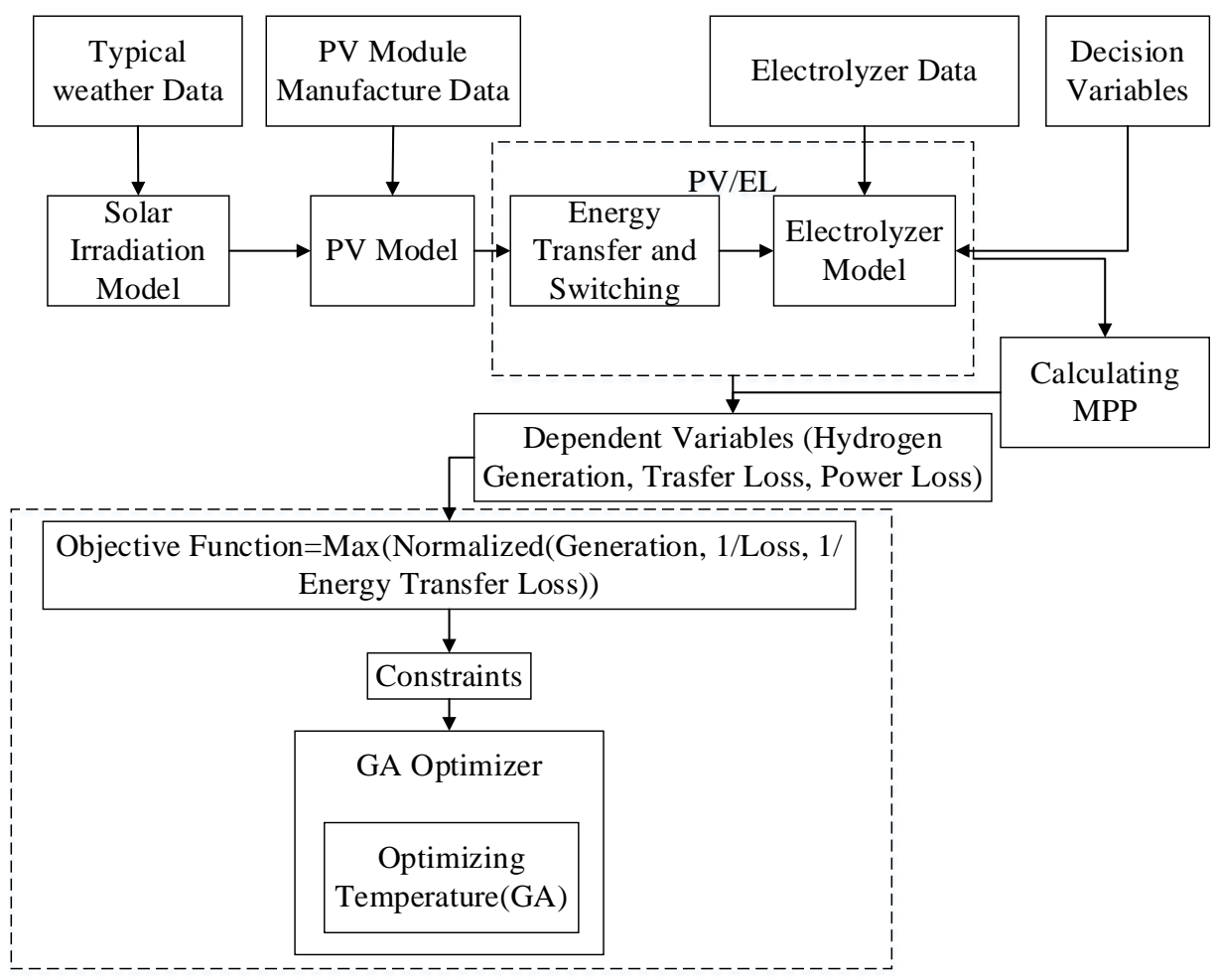

Figure 5. Simulation Procedure

\section{Results and discussions}

For the simulation of the system, actual meteorological data for diurnal temperature and irradiation of 
culmination. Based on our previous study, [32] the most appropriate values for $\beta$ "angle between surface

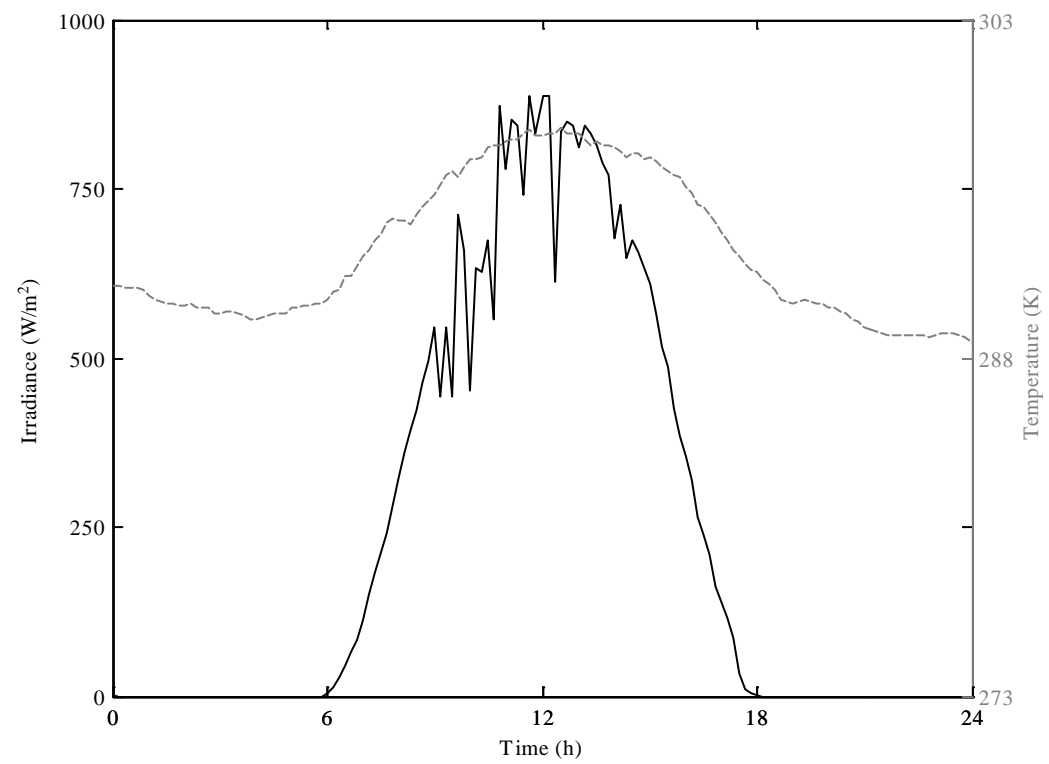

Figure 6. Temperature and Irradiance of Miami for a day

The system is optimized using genetic algorithm (GA). As it is shown in the figure 7, the optimization has

two level of GA process. So, the first level is optimizing the dimensions of the system, and the second

level is to give the optimal temperature of the system using the dimensions of each iteration as input

parameters. As it is discussed in ref [23], the minimum energy transfer loss does not necessarily leads to

maximum hydrogen production. For optimal sizing, a new objective function is proposed based on

maximum hydrogen production and minim excess power production of PV system and minimum power

Objective _ Function $=\operatorname{Maximize}\left(\frac{\operatorname{Ave}\left(\frac{P_{\text {Actual }}}{P_{M P P}}\right) \cdot \dot{n}_{H 2}}{\operatorname{Ave}\left(P_{\text {Loss }}\right)}\right)$ 


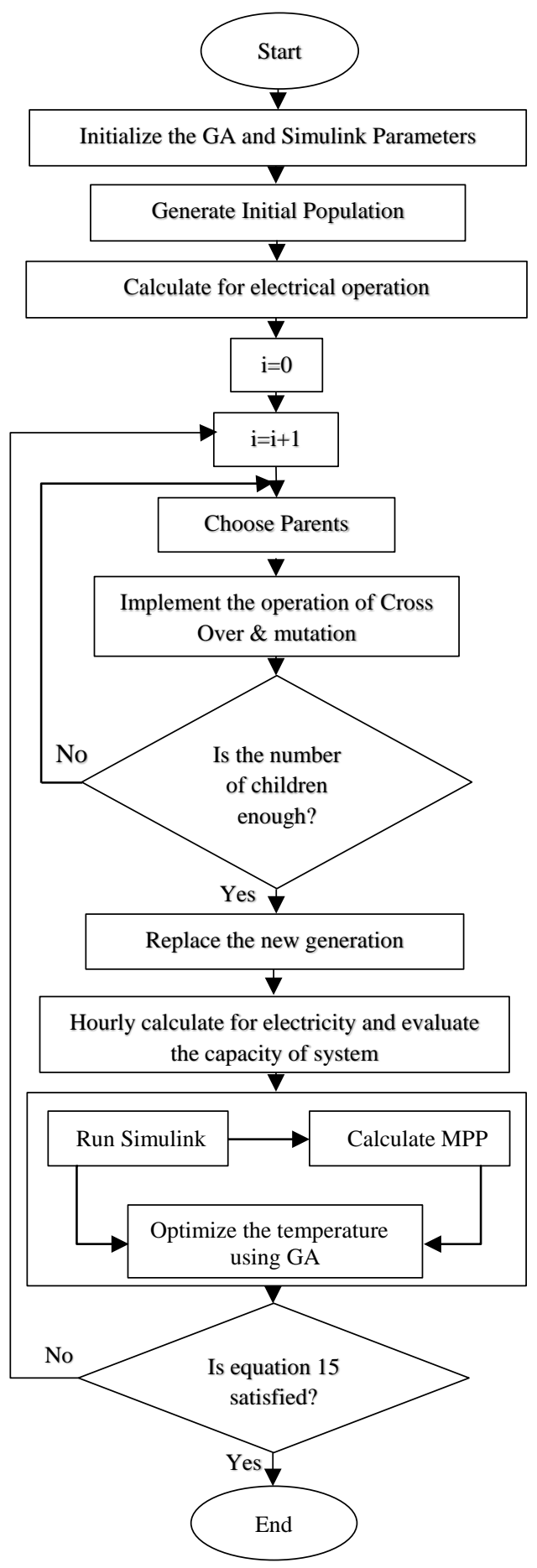

Figure 7. Flowchart of the GA optimization. 
The excess power is considered as the loss power, because it is produced when the power produced by PV

is more than nominal power of electrolyser and the energy cannot be used. As in our study, we did not

235

consider the cost of the system for optimization purpose, minimizing the excess power production could 236 be appropriate substitution, because it indirectly deals with the cost of the system. The power transfer loss

refers to the lost power because of working of the system in voltages other than voltage of maximum

power point. Also in each iteration of the optimization process, the optimal temperature is given to make

sure the best condition for the operation of the system. If we consider fixed operating temperature of

electrolyser, the results will not be accurate, because each dimension gives the maximum power in a

specific temperature. Although the temperature of the electrolyser is affected by ambient temperature and

the operating condition of the system and time, the optimum temperature can be set in the electrolyser

using the cooling system with controlled fluid flow rate and fluid temperature. The optimization results is

shown in Table 3. The optimal size of the PV array for supplying the $10 \mathrm{~kW}$ alkaline electrolyser with 21

stacks, connected in series, is $12.4 \mathrm{~kW}$ which is the combination of 2 parallel rows of panels and 133

panel in each raw. The number of solar panels in series is more than parallel because, as obvious in

Table 3. Optimization Result.

\begin{tabular}{ll}
\hline Parameter & Result \\
\hline$P V$ Nominal Power & $12.4 \mathrm{~kW}$ \\
$N_{s}$ & 133 \\
$N_{p}$ & 2 \\
$N_{c}$ & 21 \\
Average Temperature & $72^{\circ} \mathrm{C}$ \\
Average $\left(V_{\text {Direct }} / V_{\text {MPPT }}\right)$ & 0.88 \\
Average $\left(P_{\text {Direct }} / P_{\text {MPPT }}\right)$ & $95.3 \%$ \\
$P_{\text {direct_Mean }}-P_{\text {MPPT_Mean }}$ & $96 \mathrm{~W}$ \\
Hydrogen Production & $656.64 \mathrm{~mol}$ \\
Energy Loss & $5.08 \mathrm{~kJ}$ \\
Average Daily Operation Voltage & $31.25 \mathrm{~V}$ \\
Total energy Consumption & $2.42 * 10 \wedge 5 \mathrm{~kJ}$ \\
Pressure & $3.4 \mathrm{MPa}$ \\
\hline
\end{tabular}


U_I characteristic of the system is illustrated in figure 8. The average operating voltage when the PV is on

is $31.25 \mathrm{~V}$ that is the 84.5 percent of the nominal operating voltage of the system. Also, the current of the

system which follows the pattern of the voltage is shown in figure 8.b. In addition, the faraday efficiency

is given in figure 8.c. The average faraday efficiency for operating points is 79.25 percent, which is 14.6

percent less than the maximum faraday efficiency. Although at higher temperatures, the average faraday

efficiency is closer to the maximum value, its variation at proximity of nominal condition is negligible in

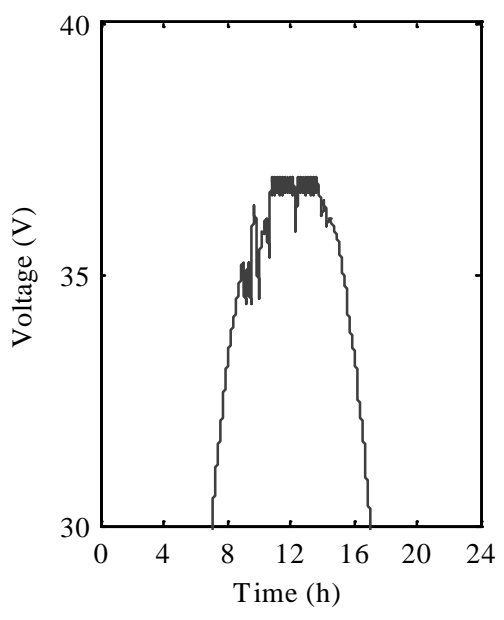

(a)

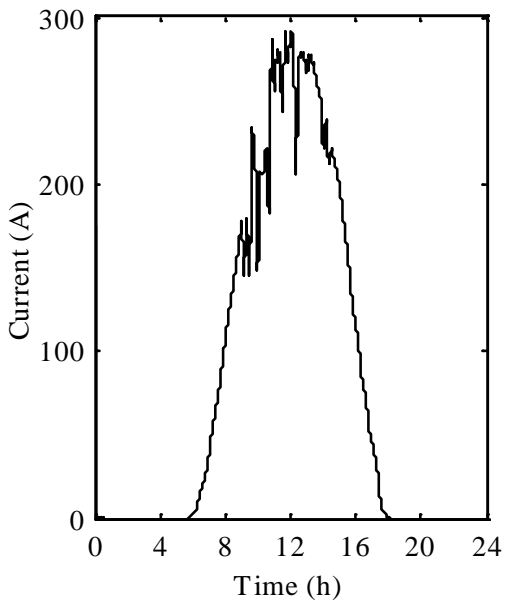

(b)

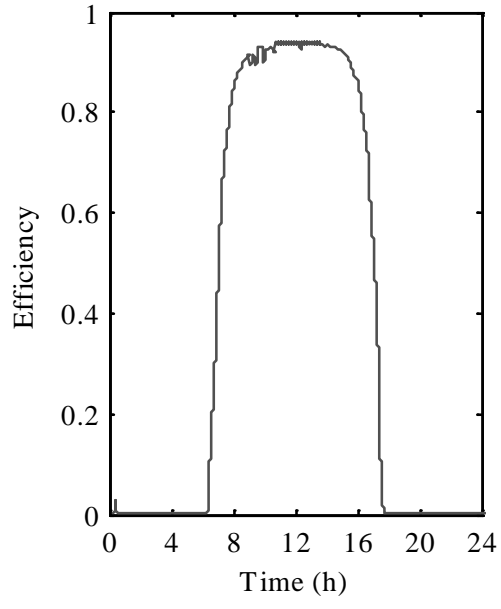

(c)

Figure 8. Electrical characteristics of direct coupled PV-electrolyser system

Figure 9 shows the power production, consumption, and excess power of the system along with focused view of unused power. The average power production is $5.61 \mathrm{~kW}$ with operating efficiency of 45 percent, which its 97.8 percent is used in the electrolyser and the rest is the unused power that has been 


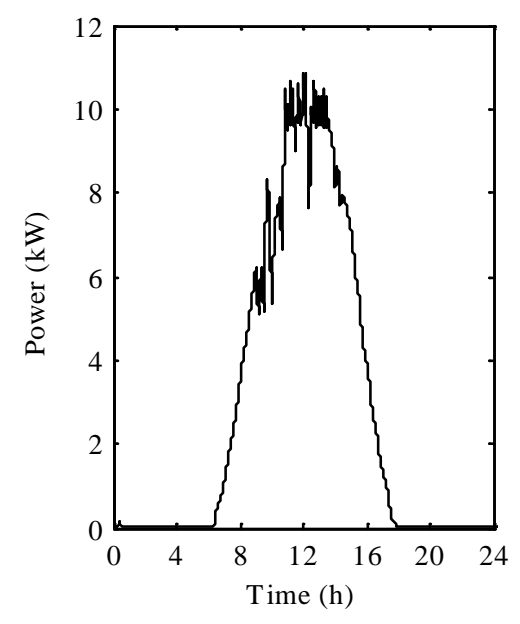

(a)

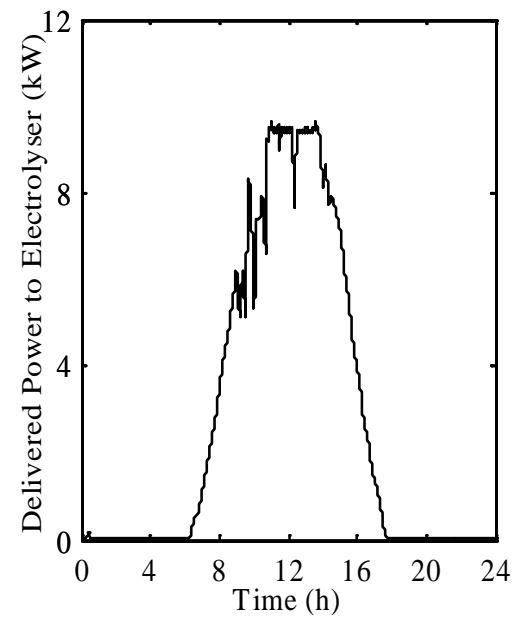

(b)

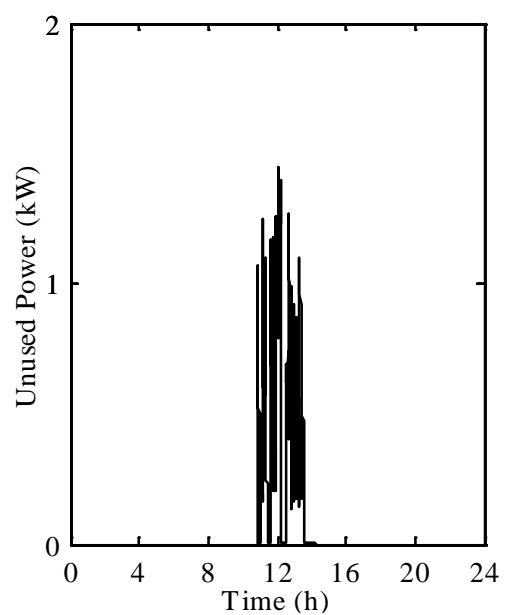

(c)

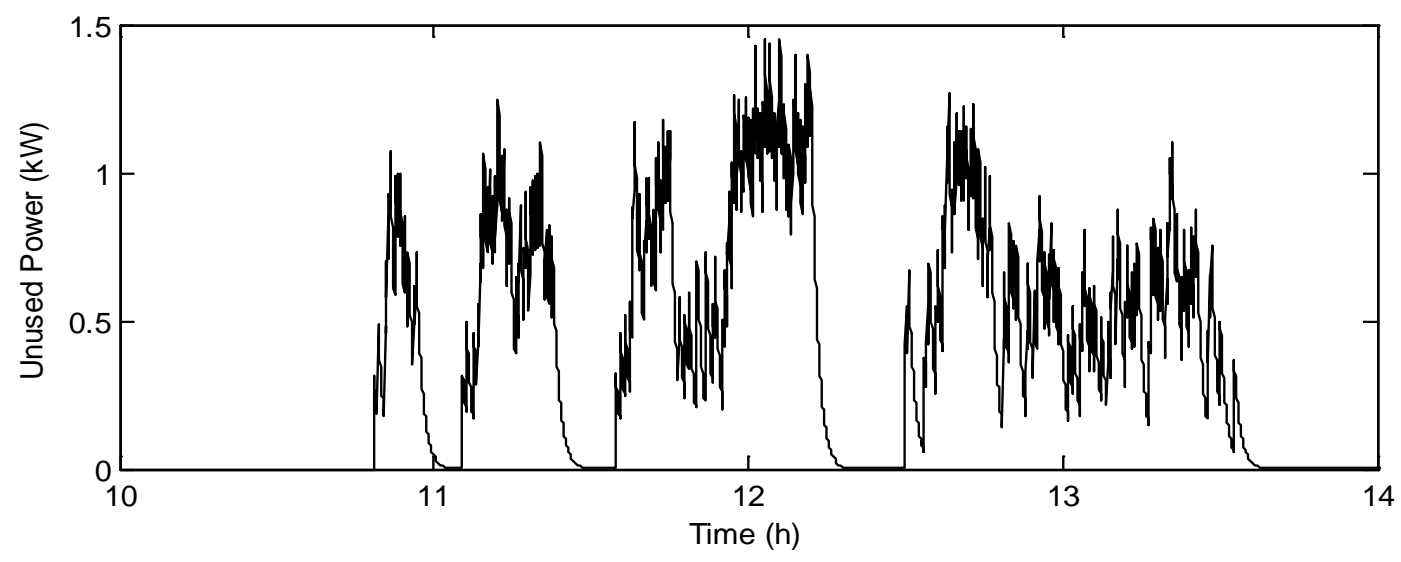

(d)

Figure 9. Produced power of photovoltaic array (a) Consumed power by electrolyser (b) and power loss (c) with

By evaluating the energy of the PV system shown in figure 10, it can be seen that the produced unused

energy is 2.08 percent of produced energy that can be neglected. Therefore, the optimum systems lost

energy is very low that the PV production is in its most efficient mode. The produced energy of the

electrolyser is just due to electrical power production and other possible ways of energy production or 


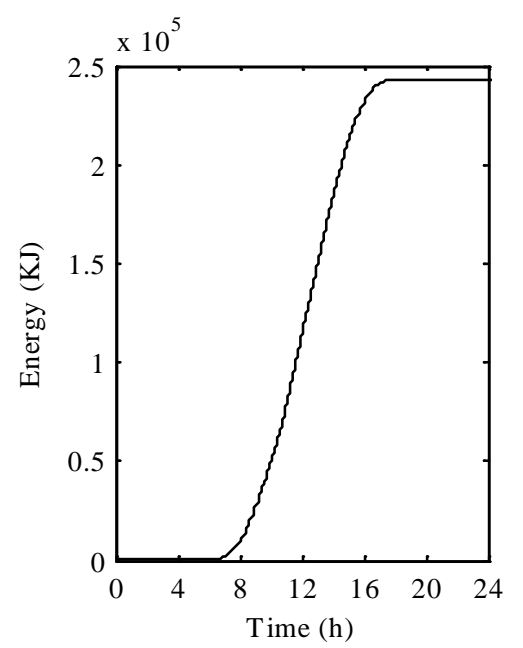

(a)

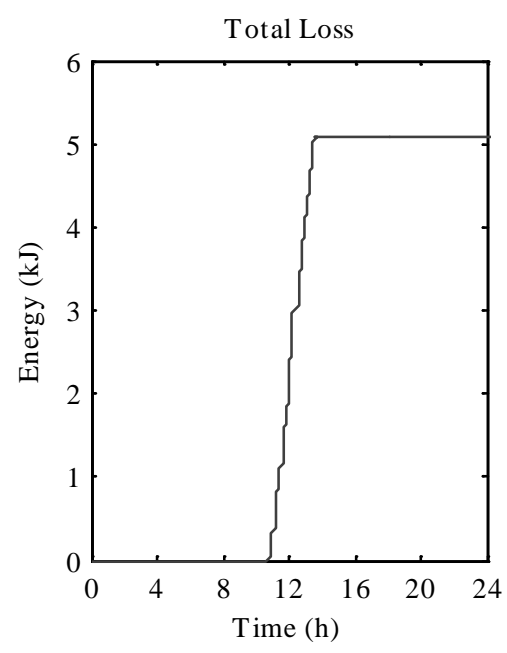

(b)

Figure 10. Energy production (a) and loss (b) of the system

The hydrogen production rate and the pressure is shown in figure 11. The average rate of hydrogen 278 production for 24 hours of the day is $0.0076 \mathrm{~mol} / \mathrm{s}$ and for operating time is $0.0151 \mathrm{~mol} / \mathrm{s}$. At the end of 279 the day, total amount of 656.64 mol hydrogen is produced and the pressure of the hydrogen storage tank 280 with initial pressure of zero is raised to $3.4 \mathrm{MPa}$.

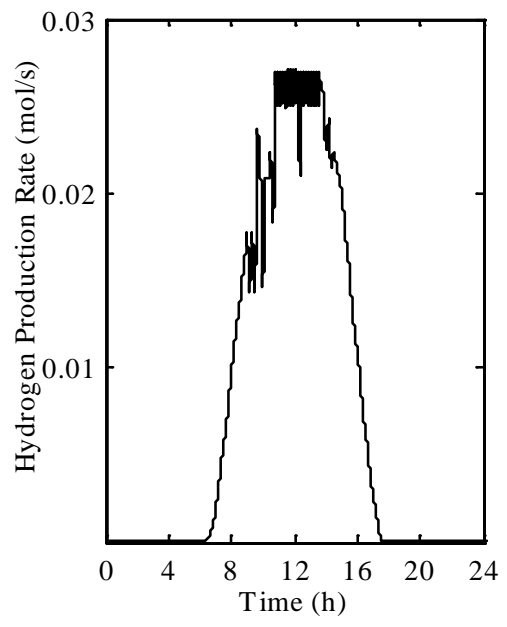

(a)

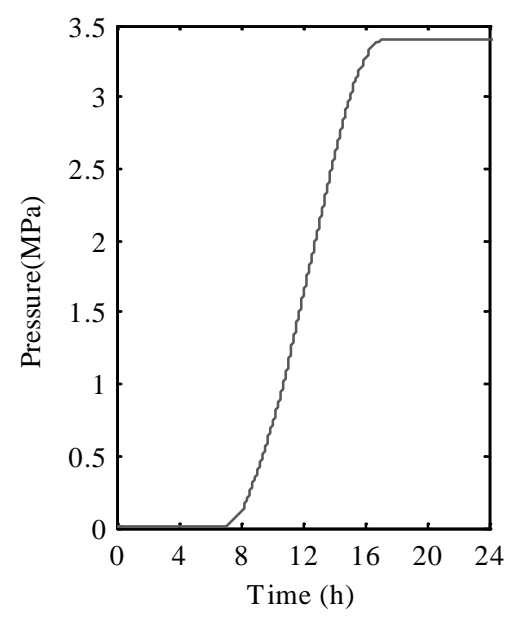

(b)

Figure 11. Hydrogen production rate of the electrolyser (a) and hydrogen storage pressure of tank (b) 
The operation of the connected PV system in both directly coupled and maximum power point modes is

shown in figure 12. As it can be seen, the power of two systems are so close to each other with only average $96 \mathrm{~W}$ lack of production in directly coupled mode. In addition, the average voltage of the directly

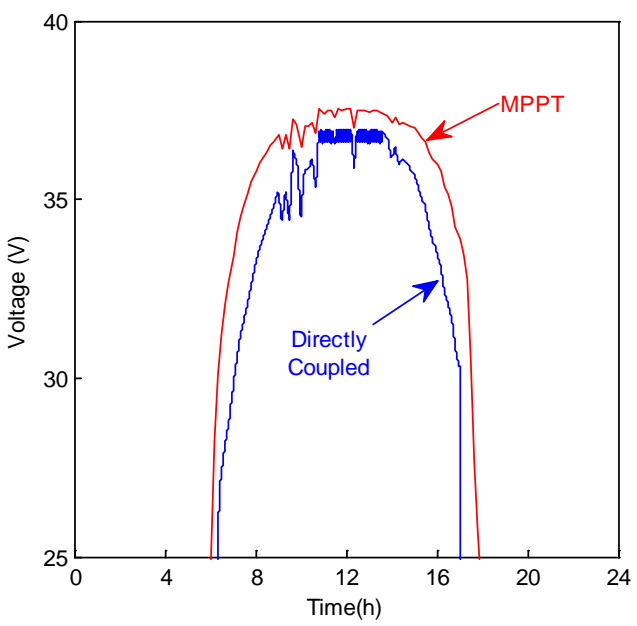

(a)

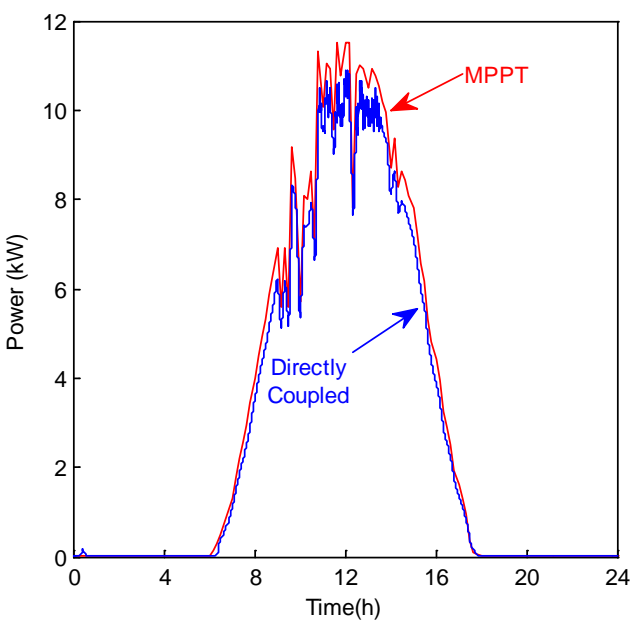

(b)

Figure 12. Voltage (a) and power production (b) of photovoltaic array in directly coupled system and with MPPT

For making the system capable of being comparative with other power production methods as the power

sources of electrolyser, the 24 hours mean characteristics of the system should be generated which is

given in Table 4. The results show that considering the evaluation of system in 24 hours period, the average amount of hydrogen production is much lower than the operating time amount.

Table 4. Average Specifications of the system in 24 hours period and in bright hours when there is irradiation

\begin{tabular}{lll}
\hline & 24 hours period & Bright hours \\
\hline Average Faraday Efficiency & 38.14 Percent & 79.25 Percent \\
Average Power consumption of electrolyser & $2.75 \mathrm{~kW}$ & $5.49 \mathrm{~kW}$ \\
Average hydrogen production rate & $0.0076 \mathrm{~mol} / \mathrm{s}$ & $0.0151 \mathrm{~mol} / \mathrm{s}$ \\
Average current & $79.13 \mathrm{~A}$ & $158.22 \mathrm{~A}$ \\
Average Voltage & $15.63 \mathrm{~V}$ & $31.25 \mathrm{~V}$ \\
Average Power loss & $0.059 \mathrm{~kW}$ & $0.118 \mathrm{~kW}$ \\
\hline
\end{tabular}


For validation of this study, a comparison between the result of proposed system and two similar systems

is given with the comparison results given in Table 5. In the first study [33], optimal direct coupling of

Table 5. Comparison of the operation of the proposed system with ref [33].

\begin{tabular}{llll}
\hline & Proposed Study & Ref [33] & Ref [24] \\
\hline Electrolyser & Advanced Alkaline electrolyser & PEM Electrolyser & PEM Electrolyser \\
Connection mode & Directly coupled & Directly coupled & Directly Coupled \\
Objective & Maximize hydrogen, minimize excess energy & Minimize the energy & Minimize $\quad$ the energy \\
& production, minimize energy transfer loss, and & loss & transfer loss \\
& optimize operating temperature & & PSO \\
Optimization method & Two level Genetic Algorithm & - & $97.8 \%$ \\
Energy Transfer & $95.3 \%$ & $94 \%$ & $5.82 \%$
\end{tabular}


Acknowledgments: This material is based on work supported by the National Science 
[1] Akyuza E, Oktay Z, Dincerb I. Performance investigation of hydrogen production from a hybrid wind-PV system. Intl. J. Hydrogen Energy 2012; 37:16623-16630.

[2] Etesami MH, Ardehali MM. Newly Developed Enhanced Imperialistic Competitive Algorithm for Design 351 Optimization of an Autonomous Hybrid Green Power System. Applied Mathematics \& Information Sciences. 2014; 8(1): 309-320.

[3] Dutta S, A review on production, storage of hydrogen and its utilization as an energy resource, Journal of 354 Industrial and Engineering Chemistry 2014; 20: 1148-1156.

[4] Dincer I, Ratlamwala T. Development of novel renewable energy based hydrogen production systems: A 356 comparative study. Energy Conversion and Management. 2013; 72:77-87.

[5] Wang M, Wang Z, Gong X, Guo Z, The intensification technologies to water electrolysis for hydrogen 358 production - A review, Renewable and Sustainable Energy Reviews, Volume 29, January 2014, Pages 573-588.

[6] Ganeshan I , Manikandan V, Sundhar V, Sajiv R, Shanthi C, Kottayil S, Ramachandran T, Regulated hydrogen 360 production using solar powered electrolyser, Intl. J. Hydrogen Energy, 2015: 1-5. Article in press.

361

[7] Scamman D, Bustamante H, Hallett S, Newborough M, Off-grid solar-hydrogen generation by passive

Electrolysis, Intl. J. Hydrogen Energy 2014;39:19855 -19868.

363

[8] Akyuz E, Coskun C, Oktay Z, Dincer I, Hydrogen production probability distributions for a PV-electrolyser system, Intl. J. Hydrogen Energy, 2011; 36: 11292-11299.

[9] Gibson T, Kelly N, Predicting efficiency of solar powered hydrogen generation using photovoltaic-electrolysis 366 devices, Intl. J. Hydrogen Energy, 2010;35: 900-911.

[10] Garcia-Valverdea R, Miguel C, Martinez-Bejar R, Urbina A, Optimized photovoltaic generator-water 368 electrolyser coupling through a controlled DC-DC converter, Intl. J. Hydrogen Energy, 2008; 33:5352 -5362

[11] Ural Z, Gencoglu M, Design and simulation of a solar-hydrogen systemfor different situations, Intl. J. 370 Hydrogen Energy, 2014;39: 8833-8840. 
[12] Garrigos A, Blanes J, Carrasco J, Lizan JL, Beneito R, Molina JA. 5 kW DC/DC converter for hydrogen

generation from photovoltaic sources. Intl. J. Hydrogen Energy, 2010;35(12):6123-30.

[13] Clarkea R, Giddeya S, Ciacchi F, Badwal S, Paul B, Andrews J. Direct coupling of an electrolyser to a solar PV

[14] Garrigos A, Blanes J, Rubiato J, A vila E, Garcıa C, Lizan J, Direct coupling photovoltaic power regulator for

stand-alone power systems with hydrogen generation, Intl. J. Hydrogen Energy, 2010;35: 10127 -10137.

[15] Abaspour A, Parsa NT, Sadeghi M, A New Feedback Linearization-NSGA-II based Control Design for PEM

[18] Khalghani MR, Khooban MH, A novel self-tuning control method based on regulated bi-objective emotional

[19] Abaspour A, Sadati SH, Sadeghi M, Nonlinear optimized adaptive trajectory control of helicopter. Control

[20] Khalghani MR, Shamsi-nejad MA, Khooban MH, Dynamic voltage restorer control using bi-objective

[21] Garcia-Valverde R, Espinosa N, Urbina A, Optimized method for photovoltaic-water electrolyser direct coupling, Intl. J. Hydrogen Energy, 2011;36: 10574-10586.

[22] Zamfirescu C, Dincer I, Assessment of a new integrated solar energy system for hydrogen production, Solar

[23] Maroufmashat A, Sayedin F, Sattari Khavas S, An imperialist competitive algorithm approach for multi- 
[24] Sayedin F, Maroufmashat A, Roshandel R, Sattari Khavas S, Optimal design and operation of a photovoltaic399 electrolyser system using particle swarm optimization, International Journal of Sustainable Energy, 2014; 1-18.

[25] Su Z, Ding S, Gan Z, Yang X, Optimization and sensitivity analysis of a photovoltaic-electrolyser direct401 coupling system in Beijing, Intl. J. Hydrogen Energy, 2014;39: 7202-7215.

[26] Yang Z, Zhang G, Lin B, Performance evaluation and optimum analysis of a photovoltaic-driven electrolyzer 403 system for hydrogen production, Intl. J. Hydrogen Energy, 2015;40:3170-3179.

[27] Ulleberg Ø. Modeling of advanced alkaline electrolyzers: a system simulation approach. Intl. J. Hydrogen 405 Energy 2003; 28:21-33. 406

[28] Khalilnejad A, Riahy G, A hybrid wind-PV system performance investigation for the purpose of maximum 407 hydrogen production and storage using advanced alkaline electrolyzer, Energy Conversion and Management, 2014; 80: 398-406.

408 409

[29] Gholami H,.Sarwat A, Hosseinian H, Khalilnejad A. Evaluation of optimal dual axis concentrated photovoltaic 410 thermal system with active ventilation using Frog Leap algorithm, Energy Conversion and Management, 2015;105: 782-790.

[30] Jena D, Ramana V. Modeling of photovoltaic system for uniform and non-uniform irradiance: A critical review,

Renewable and Sustainable Energy Reviews, 2015; 52: 400-417.

[31] Loukriz A, Haddadi M, Messalti S, Simulation and experimental design of a new advanced variable step size Incremental Conductance MPPT algorithm for PV systems, ISA Transactions, Article in press

[32] Gholami H, Khalilnejad A, Gharehpetian G, Electrothermal performance and environmental effects of optimal

[33] Paul B, Andrews J, Optimal coupling of PV arrays to PEM electrolysers in solar-hydrogen systems for remote 